the University of Hong Kong; they describe the way the problem of mental health, with particular reference to child guidance and the establishment of a clinic, is being tackled in circumstances other than our own. In an informative and interesting manner it describes these circumstances, and helps to remind us how relative our concepts are, particularly those concerning normality.

The wide range of individual differences existing within the range of normality is well emphasized by Miss Wright; however, she might also have included the important point that research has shown us that many of the socalled abnormalities of children are only apparent and pass with increasing age. Her assertion that maternal deprivation necessarily results in permanent personality damage is not valid, and there is now further evidence showing that the dangers have been overstated in the past.

Professor Priestley rightly stresses the scientific approach to mental health and the need for research, though this is not compatible with Miss Wright's subjective observations, for they require much more rigorous verification than the comments of parents and teachers which she suggests; scientific psychology aims at description and explanation, common-sense psychology seeks to understand. That the 'West may have a great deal to learn from the East' is certainly true.

\section{Changes in Body Water Compartments During Growth.}

By Bent FriIs-Hansen. (Pp. 68; 12 figures, 21 tables. Dan. Cr. 25.00.) Copenhagen: Ejnar Munksgaard. 1956.

This is a monograph of some 67 pages in which the author reports a study of the total body water and the extracellular body water, intracellular water being calculated by difference. He has used, as material, 93 subjects varying in age from birth to 16 years.

In the first chapter, after a short but interesting historical note, he discusses the methods for both estimations and comes to the conclusion that the answer varies according to the method used. He has used therefore a method to suit his own convenience. For total body water he has used the uncorrected volume of dilution of heavy water and for the extracellular water, he has used the thiosulphate volume of dilution. His normals have been obtained from various hospitals in Boston and the Rigshospital in Copenhagen.

A fair proportion of the work is devoted to a statistical study of these results in an endeavour to discover what constants, if any, would enable one to determine the size of the water compartments from either age, weight, height or a combination of these. There does not appear, however, to be a formula which is valid. It was found that the total body water expressed as a percentage of the body weight decreases with each age group from 77.6 at birth to 58.4 in adolescence. It is therefore possible to get an approximate value of the total body water using the age and weight. The extracellular water decreases in the same manner with age, and again the percentage of the body weight, varied according to age, gives one the most accurate measurement. On the other hand, the intracellular water remains relatively constant, increasing slightly if anything during the first years of life when expressed as a percentage of the total body weight.

In the last chapter there is some discussion of the meaning of these results. The main conclusion is that in all mammals there is a progressive 'drying out' as they develop from the foetal to the adult stage.

This book contains a considerable amount of work, much of which has been published in separate papers and to anyone requiring standards for body fluids it will prove of great value. There are one or two unfortunate errors. in the tables and a certain number of misprints in the text.

All Our Children. A Book for Parents. By SimON YudKIN. (Pp. $x+201$. 12s. 6d.) London: Max Reinhardt. 1956.

Although this book is written specially for parents, it will be of great interest to teachers, family doctors, paediatricians, and in fact to anyone who is closely associated with the developing child.

The great decrease in prolonged illness in early life has made the paediatrician increasingly aware of the many problems associated with the emotional development of the child. These problems have themselves increased in complexity because of the profound and rapid social changes in the last few years, and the general background of unrest and insecurity in the world.

Much valuable help will be obtained from this book in dealing with these problems of childhood and adolescence perhaps leading to the prevention of more serious disorders which can only be dealt with by a trained psychologist.

Dr. Yudkin stresses the great individual variations that occur in the intellectual and emotional growth of children who so often fail to conform to the rigid standards expected of them by educationalists, or to fit into the plan of their lives laid down for them in advance by their fond parents. Mistakes by parents are inevitable, but Dr. Yudkin points out that the lasting effect of single mistakes has received undue emphasis, too much attention often being paid to the science of 'diaperology'.

This very readable and well-produced book should be studied by everyone interested in the development of children. There can scarcely be a subject of greater importance.

\section{Ninth International Congress of Paediatrics}

The ninth International Congress of Paediatrics will be held in Montreal, Canada, from July 19 to July 25, 1959, under the chairmanship of Dr. Alan Ross, Professor of Pediatrics, the Montreal Children's Hospital, Montreal 25, Canada. 